\title{
论 文
}

\section{桂越边境地区蝙蝠病毒组研究}

\author{
燕超 ${ }^{1,2}$, 张畅 ${ }^{2}$, 徐琳 ${ }^{2}$, 孟菲 ${ }^{3}$, 吴健敏 ${ }^{3}$, 涂长春 ${ }^{2}$, 李勇 ${ }^{1^{*}}$, 何彪 ${ }^{2 *}$ \\ 1. 宁夏大学生命科学学院, 银川 750021; \\ 2. 军事科学院军事医学研究院军事兽医研究所, 吉林省人兽共患病防控重点实验室, 长春 130122; \\ 3. 广西兽医研究所, 南宁 530001 ; \\ *联系人, E-mail: liyong7732@nxu.edu.cn; heb-001001@163.com
}

收稿日期：2018-09-29; 接受日期：2018-10-16; 网络版发表日期：2019-03-06

国家自然科学基金(批准号: 31572529, 31760736)资助

摘要桂越地区包括越南和我国广西, 地理位置的战略意义突出, 该地区蝙蝠资源丰富, 且越南境内的蝙蝠携带 多种人兽共患病毒. 为了监测桂越边境地区蝙蝠病毒的跨境传播, 防范蝙蝠病毒引发新发传染病, 掌握该地区蝙 蝠携带病毒的病原本底和重要病毒遗传进化特征具有重要意义. 本研究在桂越边境采集蝙蝠样本并对其进行病 毒宏基因组学分析, 结果发现了49个科的病毒, 包括脊椎动物病毒、植物病毒、昆虫病毒和噬菌体. 根据病毒宏 基因组学结果, 对注释到的啫肝DNA病毒、博卡细小病毒、A型轮状病毒、星状病毒、弹状病毒和冠状病毒进 行检测和进化分析, 结果发现星状病毒广泛分布, 且具有丰富的遗传多样性; 其他病毒则呈局部分布, 其中嗜肝 DNA病毒、冠状病毒、轮状病毒与各自参考毒株进化关系较近, 为这些病毒的变异毒株; 而博卡细小病毒和弹状 病毒与已知病毒具有很明显的遗传差异性, 可能为病毒新种; 值得注意的是, 发现的蝙蝠轮状病毒与广西当地人 轮状病毒具有很高的同源性, 提示该病毒的跨种传播和基因重排. 本研究获得了桂越边境地区蝙蝠携带病毒的本 底数据以及部分重要病毒在该地区蝙蝠中的流行情况和遗传进化特征，为监测蝙蝠病毒的跨境传播、防范新发 病毒病提供了重要的基础数据.

关键词桂越边境地区, 蝙蝠, 病毒宏基因组学, 遗传多样性

蝙蝠属于翼手目，在种类、数量和分布上是仅次 于啮齿类且唯一会飞行的哺乳动物 ${ }^{[1]}$. 我国蝙蝠资源 丰富，目前已发现7科33属共135种，且主要分布于华 中、华南、西南等人口密集、气候湿热的地区 ${ }^{[2]}$. 蝙 蝠是多种新发和再发人兽共患病毒的自然宿主，当前 已发现的蝙蝠病毒超过200种 ${ }^{[3]}$ ，其中不乏马堡病

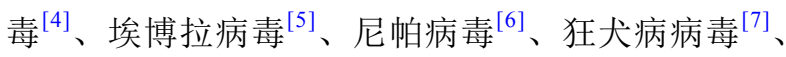
SARS样冠状病毒 ${ }^{[8]}$ 等烈性病原体.
东南亚地处热带地区，人口稠密，蝙蝠资源丰富， 该地区也是多种新发传染病的暴发和流行区，如蝙蝠 源的尼帕病毒自1998年首次在马来西亚引发猪和人的 尼帕病毒病以来, 经常在东南亚和南亚一带造成疫病 的暴发, 导致人的死亡 ${ }^{[9]}$. 除了尼帕病毒以外, 该地区

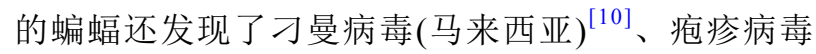
$(\text { 菲律宾 })^{[11]}$ 、冠状病毒(菲律宾) ${ }^{[12]}$ 、多瘤病毒(印度尼 西亚 $)^{[13]}$ 、汉坦病毒(越南) ${ }^{[14]}$ 等. 桂越边境地区作为我

引用格式: 燕超, 张畅, 徐琳, 等. 桂越边境地区蝙蝠病毒组研究. 中国科学: 生命科学, 2019, 49: 266-279

Yan C, Zhang C, Xu L, et al. Metagenomic analysis of bat virome in the Guangxi-Vietnam border area (in Chinese). Sci Sin Vitae, 2019, 49: 266-279, doi: 10.1360/N052018-00191 
国一条连通东南亚的主要交通要道，在“一带一路”倡 议的大力推动下，物资贸易、人员往来也愈发频繁， 然而随之而来的疫病跨境传播风险也显著增加，给我 国外来病的防控带来不小的挑战. 因此全面掌握该地 区蝙蝠携带病毒的病原本底和遗传进化对于监测蝙蝠 病毒的跨境传播和防范其引发疫病，具有非常重要的 公共卫生意义.

本研究运用病毒宏基因组学技术对采集自该地区 的蝙蝠进行了病毒组分析, 发现了丰富的病毒信息, 并 针对重要病毒进行了检测和遗传演化分析，为掌握该 地区蝙蝠病毒的多样性提供了重要的基础数据.

\section{1 材料与方法}

\section{1 蝙蝠采集}

2016年, 在桂越边境地区7个点的蝙蝠栖息地进行 样品采集, 采样地点分别为: 靖西市禄峒镇(JX), 靖西 市安宁乡(AN), 崇左市龙州县(LZ), 崇左市宁明县 (NM), 防城港市东兴市(DX), 防城港市防城区(FC), 钦 州市灵山县(LS). 蝙蝠通过网捕捉后立即在当地动物 疫控中心进行解剖, 取出直肠(含内容物)和肺脏, 分别 装入 $2 \mathrm{~mL}$ 冻存管，然后用干冰运回实验室，并保存在 $-80^{\circ} \mathrm{C}$ 的冰箱. 蝙蝠种类首先通过形态学进行鉴定, 并 进一步通过蝙蝠肌肉线粒体Cyt $b$ 基因进行确认 ${ }^{[15]}$. 此 研究严格按照军事科学院军事医学研究院军事兽医研 究所动物福利委员会相关规定执行.

\section{2 样品处理}

每只蝙蝠的两种组织各取约 $0.1 \mathrm{~g}$, 按地区混合为 7 组, 每组按 $1: 10(\mathrm{w} / \mathrm{v})$ 加入无菌 $\mathrm{SM}$ 缓冲液 $(50 \mathrm{mmol} / \mathrm{L}$ Tris, $10 \mathrm{mmol} / \mathrm{L} \mathrm{MgSO}_{4}, 0.1 \mathrm{~mol} / \mathrm{L} \mathrm{NaCl}, \mathrm{pH} 7.5$ ), 使 用玻璃研磨器彻底研磨; 研磨液于 $4^{\circ} \mathrm{C} 、 12000 \mathrm{r} / \mathrm{min}$ 离 心 $10 \mathrm{~min}$ ，取上层清液; 随后用 $0.22 \mu \mathrm{m}$ 孔径的低蛋白 吸附针头滤器(Millipore公司, 美国)过滤, 除掉组织碎 片、细菌和其他杂质; 滤过液加入Turbo DNA酶(Ambion公司，美国)和Benzonase核酸酶(Novagen公司，德 国)在 $37^{\circ} \mathrm{C}$ 孵育 $1 \mathrm{~h}$ 消化掉宿主的基因组和外源基因; 消化液使用TRIzol(大连宝生物公司)法结合RNeasy mini Kit试剂盒(Qiagen公司, 德国)提取总核酸, 并使用 带标签序列的随机引物进行反转录得到 $\mathrm{cDNA}$; 随后 使用Klenow酶(TaKaRa公司, 日本)合成双链cDNA; 最
后使用标签序列进行不依赖序列的单引物扩增. PCR 扩增产物用QIAquick PCR Purification Kit试剂盒(Qiagen公司)进行纯化，将纯化合格的PCR产物进行高通 量测序.

\section{3 高通量测序及生物信息分析}

纯化后的PCR产物使用超声随机打断到 $200 \mathrm{bp}$ 大 小, 依次通过末端修复、添加 $3^{\prime}-\mathrm{dA}$ 突起、连接配体等 最后构建PCR-free文库，文库质检合格后进行Illumina HiSeq 2500 PE125双端测序. 得到的原始数据首先去 除含 $\mathrm{N}(\geq 3 \mathrm{bp})$ 的reads和配体序列污染，同时去除连续 低质量序列和重复污染，得到高质量的reads; 然后使 用SOAP去除宿主基因组，并使用脚本将reads进行拼 接(限定最小重叠长度为 $10 \mathrm{bp}$ 且错配为 1 ), 然后进行 $\mathrm{BLAST} n$ 和BLAST $x$ 注释, 参考数据库为 GenBank的非 咒余核酸和蛋白数据库, 限定条件为 $e$ value $\leq 10^{-3}$. 注 释到病毒的序列进行SeqMan v7再拼接得到重叠序列 (contigs), 其中长度超过 $300 \mathrm{bp}$ 的用于进一步分析.

\subsection{PCR检测}

针对一些拼接好的病毒重叠序列, 通过BLAST比 对，找到并下载GenBank相应参考序列，参考已有的文 献, 使用Primer Premier 5.0软件分别设计引物, 同时也 使用本实验室前期建立的方法，对相应的病毒进行检 测. 组织样品研磨后离心取上层清液(同方法1.2), 使 用试剂盒(Qiagen公司)分别提取DNA和RNA，RNA使 用反转录酶 (大连宝生物公司) 反转录为 $\mathrm{cDNA}$ 连同 DNA进行PCR检测. PCR使用 $25 \mu \mathrm{L}$ 体系: $2 \times$ Master$\operatorname{Mix}$ (天根公司) $12.5 \mu \mathrm{L} 、 \mathrm{ddH}_{2} \mathrm{O} \quad 9.5 \mu \mathrm{L}$ 、上游引物 $(10 \mathrm{pmol} / \mu \mathrm{L}) 1 \mu \mathrm{L}$ 、下游引物 $(10 \mathrm{pmol} / \mu \mathrm{L}) 1 \mu \mathrm{L}$ 、 DNA或cDNA 模板 $1 \mu \mathrm{L}$. PCR 常规条件为 $94^{\circ} \mathrm{C}$ 预变性 $3 \mathrm{~min}$; 然后 $94^{\circ} \mathrm{C} 30 \mathrm{~s}, 53^{\circ} \mathrm{C} 30 \mathrm{~s}, 72^{\circ} \mathrm{C} 40 \mathrm{~s}$, 外套反应 和内套反应各 35 个循环， $72^{\circ} \mathrm{C}$ 延伸 $7 \mathrm{~min}$ ，不同引物的 退火温度根据 $T_{\mathrm{m}}$ 值适当调整. 所有PCR检测使用 $\mathrm{ddH}_{2}$ $\mathrm{O}$ 作为阴性对照, 且不使用阳性对照, PCR阳性产物直 接送吉林省库美生物公司测序.

\section{5 进化分析}

测序得到的序列经过BLAST查找并下载近缘参考 序列，同时从GenBank中下载病毒的经典参考毒株和国 内类似毒株序列. 所有序列首先通过Clustal W对齐后手 
动裁剪到一定长度后再次对齐, 然后使用MEGA7.0软 件进行系统发生分析，进化树选择基于Maximum Composite Likelihood算法的邻接法(neighbor-joining method，NJ)，Bootstrap检验设定为 1000 个重复．序列 同源性使用DNAstar中的MegAlign软件进行计算.

\section{6 序列提交}

本研究组装得到的contigs和检测片段，全部提交 到GenBank，登陆号为MK0642 10-MK064215 和 MK004954-MK005002.

\section{2 结果与分析}

\section{1 样品信息}

2016年8月，在广西桂越边境地区7个地点(崇左市 宁明县、崇左市龙州县、钦州市灵山县、防城港市防
城区、防城港市东兴市、百色市靖西市禄峒镇平江 村、百色市靖西市安宁乡安宁街)共采集到268只蝙 蝠. 经物种鉴定后, 发现这些蝙蝠属于 4 科 6 属 11 种 (表1).

\section{2 高通量测序结果}

通过高通量测序，获得8856235条高质量reads, reads的平均长度为 $187 \mathrm{bp}$. 经比对后, 获得注释为病毒 的 reads有 449500 条, 占总的读长数量的 $5.1 \%$. 其中 $83.0 \%(373066 / 449500)$ 的序列与脊椎动物病毒相关, 主要包括痘病毒科(Poxviridae)、腺病毒科(Adenoviridae)、指环病毒科(Anelloviridae)、圆环病毒科(Circoviridae)、细小病毒科(Parvoviridae)、小双节RNA病毒 (Picobirnaviridae)、呼肠孤病毒科(Reoviridae)、冠状 病毒科(Coronaviridae)、星状病毒科(Astroviridae)、 杯状病毒科(Caliciviridae)、黄病毒科(Flaviviridae)、

\section{表 1 蝙蝠样品信息及病毒PCR检测情况}

Table 1 Bat sampling information and virus detection by PCR

\begin{tabular}{|c|c|c|c|c|c|c|c|c|c|}
\hline 地点 & 分组 & 种类 & 数量 & $\begin{array}{l}\text { 星状病毒 } \\
\text { (astrovirus) }\end{array}$ & $\begin{array}{c}\text { 冠状病毒 } \\
\text { (coronavirus) }\end{array}$ & $\begin{array}{l}\text { 轮状病毒 } \\
\text { (rotavirus) }\end{array}$ & $\begin{array}{c}\text { 弹状病毒 } \\
\text { (rhabdovirus) }\end{array}$ & $\begin{array}{c}\text { 博卡病毒 } \\
\text { (bocavirus) }\end{array}$ & $\begin{array}{l}\text { 喷肝DNA病毒 } \\
\text { (hepadnavirus) }\end{array}$ \\
\hline 崇左市宁明县 & Pool 1 & 普通长翼蝠 & 38 & $10.5 \%(4)$ & & & & $5.3 \%(2)$ & \\
\hline \multirow{2}{*}{ 崇左市龙州县 } & \multirow{2}{*}{ Pool 2} & 黑䯿墓蝠 & 35 & $2.9 \%(1)$ & & & & & \\
\hline & & 大蹄蝠 & 21 & & & & & & \\
\hline 钦州市灵山县 & Pool 3 & 小黄蝠 & 43 & $4.7 \%(2)$ & $14.0 \%(6)$ & $2.3 \%(1)$ & $13.95 \%(6)$ & & \\
\hline \multirow{2}{*}{ 防城港市防城区 } & \multirow{2}{*}{ Pool 4} & 中蹄蝠 & 20 & $5.0 \%(1)$ & $15.0 \%(3)$ & & & & \\
\hline & & 中菊头蝠 & 21 & $9.5 \%(2)$ & & & & & \\
\hline \multirow{4}{*}{ 防城港市东兴市 } & \multirow{4}{*}{ Pool 5} & 长翼蝠 & 1 & $100.0 \%(1)$ & & & & & \\
\hline & & 果树蹄蝠 & 2 & & & & & & \\
\hline & & 中蹄蝠 & 10 & $10.0 \%(1)$ & & & & & \\
\hline & & 中菊头蝠 & 27 & $11.1 \%(3)$ & & & & & $3.7(1)$ \\
\hline \multirow{5}{*}{ 靖西市禄峒镇 } & \multirow{5}{*}{ Pool 6} & 大蹄蝠 & 9 & & & & $11.1 \%(1)$ & & \\
\hline & & 果树蹄蝠 & 3 & & & & & & \\
\hline & & 丑蹄蝠 & 8 & $37.5 \%(3)$ & & & $12.5 \%(1)$ & & \\
\hline & & 中蹄蝠 & 5 & $60.0 \%(3)$ & & $20.0 \%(1)$ & & & \\
\hline & & 三叶蹄蝠 & 4 & & & & & & \\
\hline \multirow{5}{*}{ 靖西市安宁乡 } & \multirow{5}{*}{ Pool 7} & 大蹄蝠 & 6 & $16.7 \%(1)$ & & & & & \\
\hline & & 果树蹄蝠 & 1 & & & & & & \\
\hline & & 中蹄蝠 & 4 & $25.0 \%(1)$ & & & & & \\
\hline & & 托氏菊头蝠 & 7 & $28.6 \%(2)$ & & & & & \\
\hline & & 皮氏菊头蝠 & 3 & $66.7 \%(2)$ & & & & & \\
\hline 合计 & & & 268 & $10.1 \%(27)$ & $3.4 \%(9)$ & $0.8 \%(2)$ & $3.0 \%(8)$ & $0.8 \%(2)$ & $0.4 \%(1)$ \\
\hline
\end{tabular}


小RNA病毒科(Picornaviridae)、嗜肝DNA病毒科(Hepadnaviridae)、弹状病毒科(Rhabdoviridae)等19个病 毒科; $1.2 \%(5370 / 449500)$ 的序列与昆虫病毒相关, 主要 包括囊泡病毒科(Ascoviridae)、杆状病毒科(Baculoviridae)、虹彩病毒科(Iridoviridae)、异疮疹病毒科 (Alloherpesviridae)、双顺反子病毒科(Dicistroviridae)、传染性软腐病毒科(Iflaviridae)、汉坦病毒科 (Hantaviridae)等17个病毒科； $0.4 \%(1574 / 449500)$ 的序 列注释到植物病毒, 主要包括雀麦花叶病毒科(Bromoviridae)、花椰菜花叶病毒科(Caulimoviridae)、双生病 毒科(Geminiviridae)、矮化病毒科(Nanoviridae)、双 分病毒科(Partitiviridae)等 13 个病毒科; 另外还有 $15.5 \%$ (69490/449500)的序列注释到噬菌体, 包括长尾噬菌体 科(Siphoviridae)、短尾噬菌体科(Podoviridae)等, 详细 病毒注释信息见图1.

\subsection{Contigs 分析}

小双节RNA病毒. 小双节RNA病毒(picobirnavirus，PBV)属于小双节RNA病毒科(Picobirnaviridae), 其基因组含有 2 个双链的RNA片段, 分别为 $\mathrm{S} 1$ 和 $\mathrm{S} 2$, 较 大的片段 $\mathrm{S} 1$ 长 $2.4 \sim 2.6 \mathrm{~kb}$, 编码 3 个可读框(open reading frame, ORF), 较小的 $\mathrm{S} 2$ 长1.5 1.9 kb, 编码RNA依赖性 RNA聚合酶(RNA dependent RNA polymerase, RdRp) 基因 ${ }^{[16]}$. 本研究获得248条小RNA病毒reads, 拼接后获 得 2 个长度为 1180 和 $1277 \mathrm{bp}$ 的contigs (BtPBV VIRESC1和VIRES-C2, 图2A), 分布小双节RNA病毒的S2片 段编码 $\mathrm{RdRp}$ 基因, 其中长度为 $1180 \mathrm{bp}$ 的 $\mathrm{C} 1$ 与长度 $1277 \mathrm{bp}$ 的 C2有 $1112 \mathrm{bp}$ 的重叠, 彼此之间同源性为 $32.9 \%$; 用该重叠区域与各代表株进行进化分析, 发现 $\mathrm{C} 1$ 与 $\mathrm{C} 2$ 分别处于不同的进化分支, 其中 $\mathrm{C} 1$ 与我国喜马 拉雅旱獭携带的MaPBV C324599, MaPBV C225309和 PBV-monkey/USA/196-06的形成一个进化分支, 且与 $\mathrm{MaPBV} \mathrm{C} 324599$ 的同源性最高为 $62.7 \%$; 而 $\mathrm{C} 2$ 与 MaPBV-C424165和骆驼携带的DrPBV-C4782-2013形 成一个进化支, 且与该进化分支的MaPBV-C424165的 同源性最高为为 $62.3 \%$ (图2A).

杯状病毒. 杯状病毒(calicvirus, CV)属于杯状病毒 科, 为单股正链 RNA病毒, 基因组大小为7.4 8.3 kb (https://talk.ictvonline.org/taxonomy/). 本研究获得 227 条杯状病毒reads, 拼接后获得 2 个 1152 和 $672 \mathrm{bp}$ 的contigs (BtCV VIRES-C1和VIRES-C2), 分布于杯状病毒
ORF1基因处, $\mathrm{C} 1$ 完全覆盖 $\mathrm{C} 2$ (图2B), 且彼此同源性为 $52.7 \%$. 用该重叠区域与代表株进行序列比较和进化 分析, 发现 $\mathrm{C} 1$ 和 $\mathrm{C} 2$ 与 $\mathrm{BtSaV}$ TLC58/HK以及 BtSaVHong Kong处在同一个进化分支, 而 $\mathrm{C} 2$ 处在该分支外 侧, 其中 C 1 与 TLC $58 / \mathrm{HK}$ 的同源性最高为 $58.5 \%$, 而 $\mathrm{C} 2$ 与其同源性略低为 $57.6 \%$ (图2B).

多瘤病毒. 多瘤病毒(polyomavirus, PyV)是一种常 见的致癌病毒, 分布广泛, 目前ICTV收录5 属88种多瘤 病毒(https://talk.ictvonline.org/taxonomy/). 本研究获得 16 条多瘤病毒的reads, 拼接后获得 1 个 $615 \mathrm{bp}$ 的contig (BtPyV VIRES-C1), 分布于多瘤病毒的VP2基因(图 $2 \mathrm{C})$, 序列比对和进化分析发现其与蝙蝠源 BtPyV SUB 13/25 和SUB13/14处在同一个进化分支, 与 SUB13/25核苷酸同源性最高为 $93.0 \%$ (图2C).

丙肝病毒. 丙肝病毒(hepacivirus, HCV)于黄病毒 科, 基因组大小为 $9.0 \sim 13 \mathrm{~kb}$, 属于正链RNA病毒, 其基 因组 $3^{\prime}$ 末端缺少poly(A)尾巴, 丙肝病毒是人最具传染 性的病毒之一, 是造成人丙型肝炎以及肝细胞癌的主 要元凶 ${ }^{[17]}$. 本研究获得 24 条黄病毒reads, 拼接后得到 1 个333 bp的contig(BtHCV VIRES-C1), 其分布于丙肝 病毒 L基因的NS3位置(图2D), 序列比较与进化分析显 示 1 与另一株蝙蝠源BtHCV L-PDB-112处在同一个 进化分支，核苷酸同源性为 $71.2 \%$, 而该片段与人的 $\mathrm{HCV}$ 同源性为 $54 \%$ 左右(图2D).

\subsection{PCR 检测及进化分析}

嗜肝DNA病毒. 嗜肝DNA病毒(hepadnavirus)的代 表种为人的乙型肝炎病毒(hepatitis B virus, HBV), 其基因组由部分双链DNA组成, 基因组大小为 3.0 $3.3 \mathrm{~kb}^{[18]}$. 本研究的病毒宏基因组学结果发现了 48 条 reads注释到嗜肝DNA病毒, 拼接后得到 8 个contigs, 序 列比对发现这些contigs与当前所有已知病毒具有明显 的差异, 提示可能为新的病毒变异株. 运用本实验室建 立的检测方法对所有的样品进行检测 ${ }^{[19]}$, 引物及扩增 片段信息见表 2 , 结果从东兴市的中菊头蝠的肠道组 织中检测到一株蝙蝠肝炎病毒(bat hepatitis B virus, BtHBV), 命名为DXRA22, 阳性率为 $2.5 \%(1 / 40)$ (表1). 对此株病毒与当前已知毒株进行进化分析, 发现该病 毒与从浙江龙泉大蹄蝠中发现的 Neixiang-Rpu-92和 贵州蝙蝠病毒Guizhou-Ms-269形成一个进化分支，核 苷酸同源性分别为 $90.6 \%$ 和 $90.9 \%$, 同时与广西的河池 
燕超等: 桂越边境地区蝙蝠病毒组研究

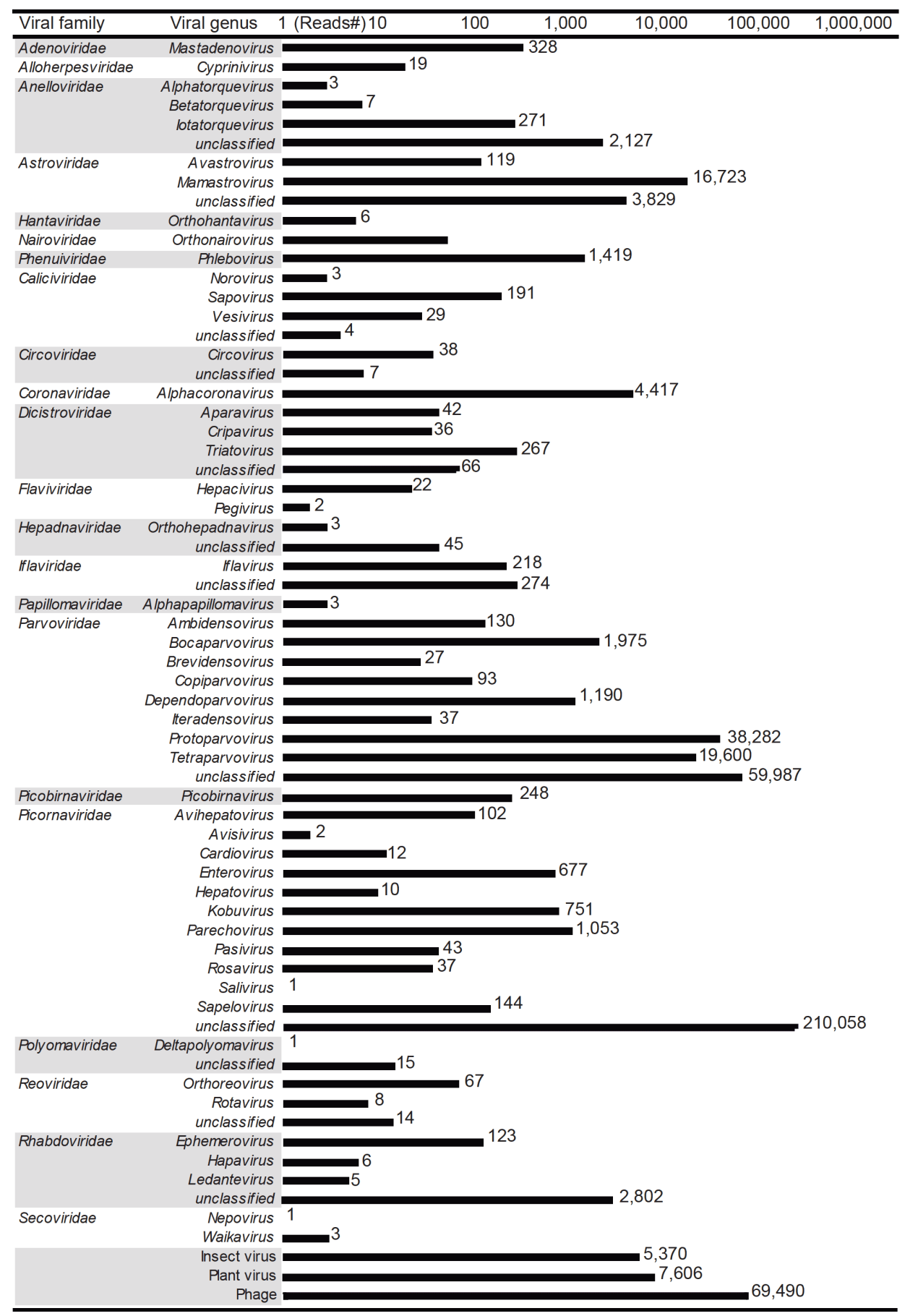

图 1 病毒宏基因组学分析结果总结

Figure 1 Summary of the number of reads related to viruses revealed by viral metagenomics

大蹄蝠发现的HCGR 1 和HCGR2的同源性为 $90.6 \%$, 而 与云南普洱果树蹄蝠病毒PEPR同源性为 $86.8 \%$ ，与 2008年缅甸发现的776毒株同源性为 $80.6 \%$ (图3A).
博卡病毒. 博卡病毒(bocavirus)属于细小病毒科 (Parvoviridae)细小病毒亚科(Parvovirinae)博卡病毒属 (Bocaparvovirus), 目前ICTV收录21个种(https://talk.ict- 
A Picobirnavirus

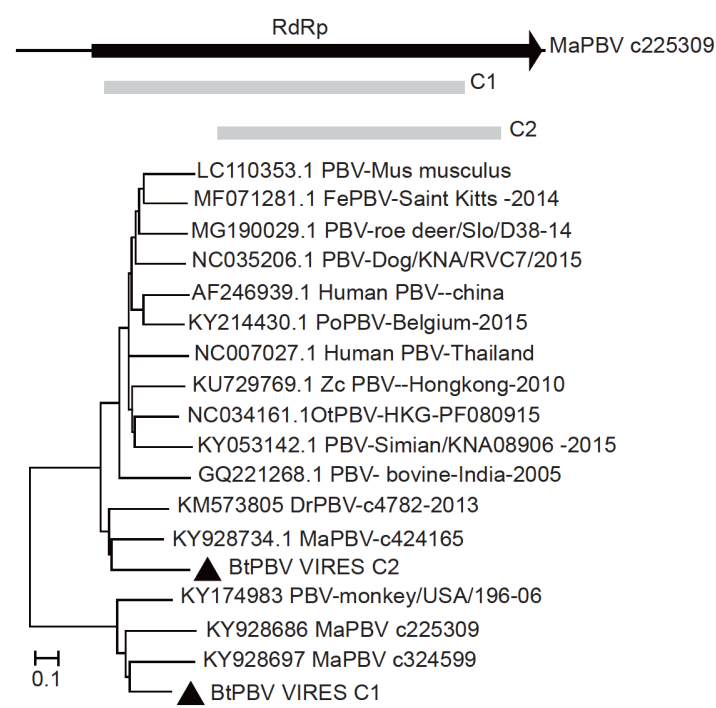

C Polyomavirus

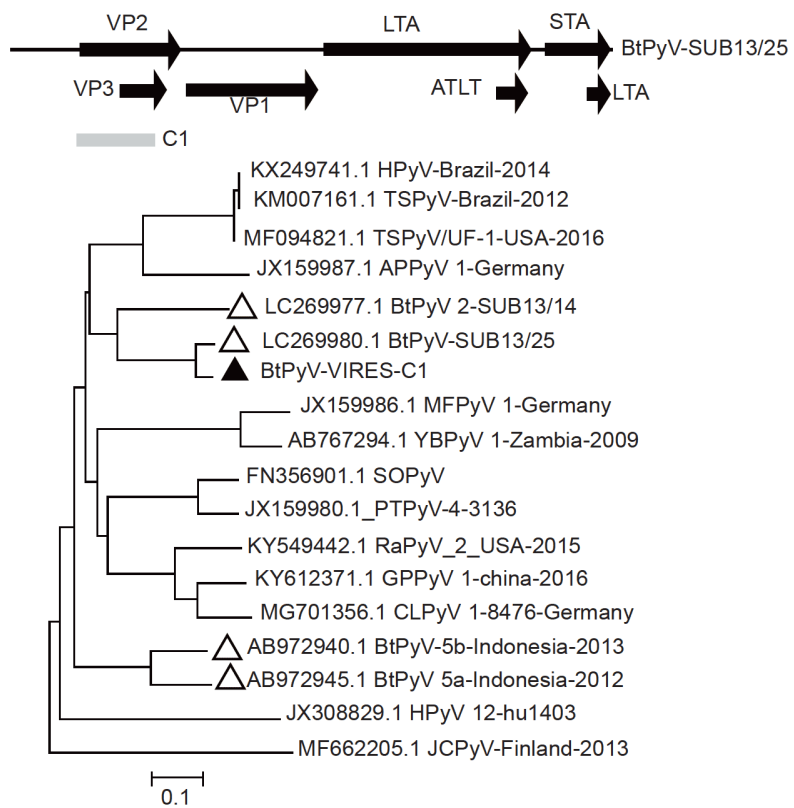

B

Calicvirus
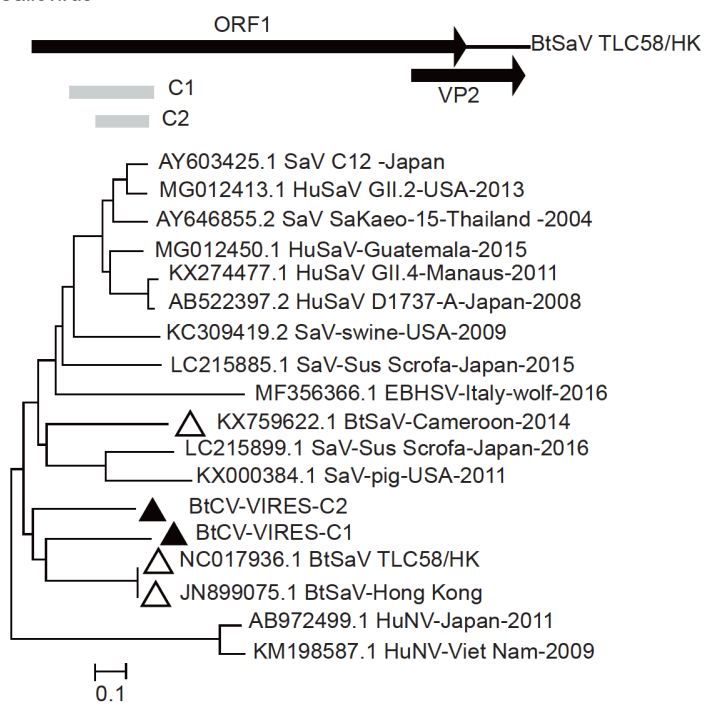

D

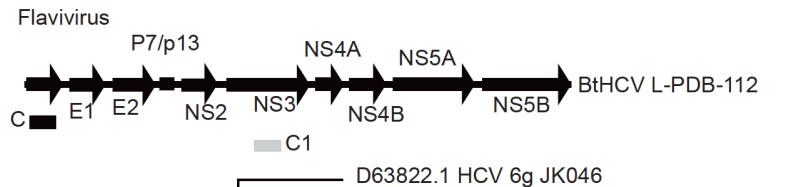

图 2 组装得到的小RNA病毒 $(A) 、$ 杯状病毒 $(B) 、$ 多头瘤病毒 $(C)$ 和丙肝病毒(D)的contigs(灰色框)在参考基因上的位置, 以及 代表性contigs与参考毒株的进化分析, 本研究组装的contigs在进化树上用黑三角表示, 其他蝙蝠病毒序列用白三角表示

Figure 2 Phylogenetic analyses of contigs (filled triangles) of picornavirus (A), calicivirus (B), polyomavirus (C) and hepacivirus (D) with other batrelated viral sequences marked by open triangles. Those contigs (grey boxes) are mapped against reference sequences to illustrate their position.

vonline.org/taxonomy/). 本研究共获得博卡病毒的 reads 1975条，拼接后共获得46条博卡病毒的contigs. 运用本实验室建立的检测方法对所有的样品进行检

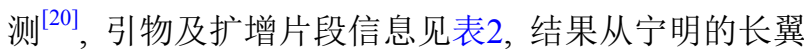
蝠肠道组织中检测到两株博卡病毒，分别命名为Bat
Bocavirus (BtBCV) NMMS30和BtBCV NMMS32, 阳 性率为 $5.3 \%(2 / 38)$, 此 2 株病毒之间同源性为 $100.0 \%$. 多序列比对和进化分析发现，这2株病毒的扩增片段 $(620 \mathrm{bp})$ 与 2008 年缅甸长翼蝠携带的WM40形成一个 进化分支，同源性高达 $94.5 \%$ ，而与云南蝙蝠携带的 
A Bat hepatitis virus
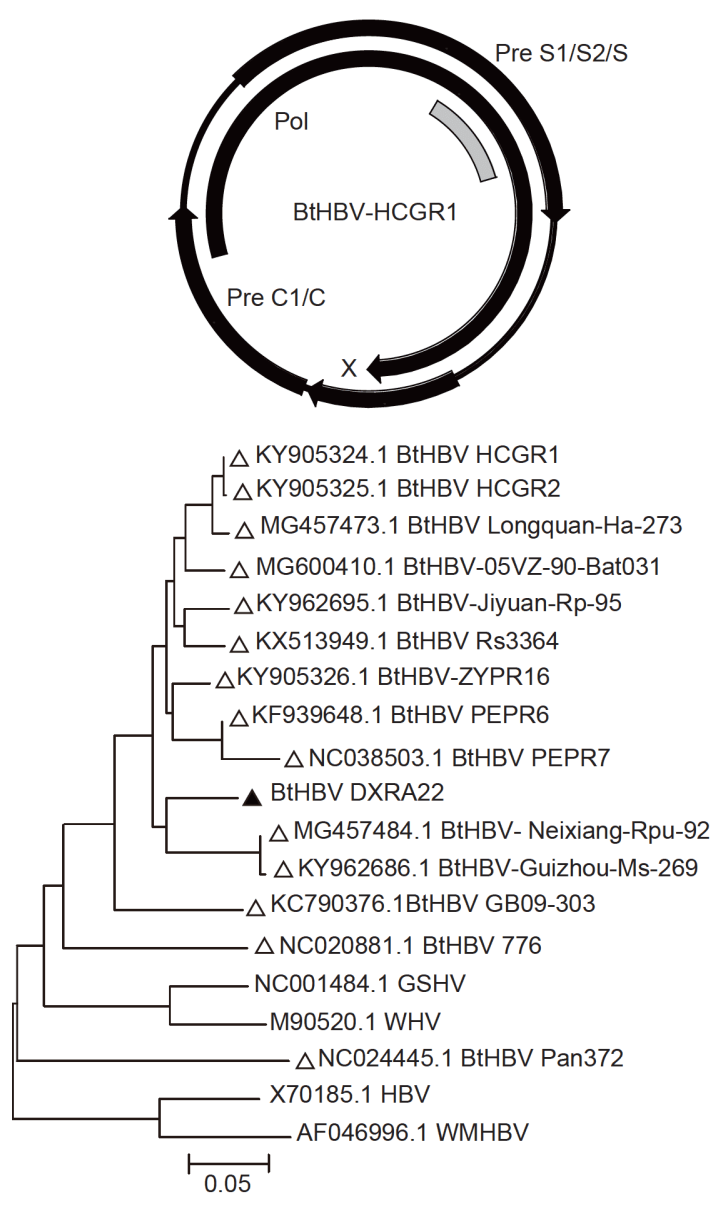

B

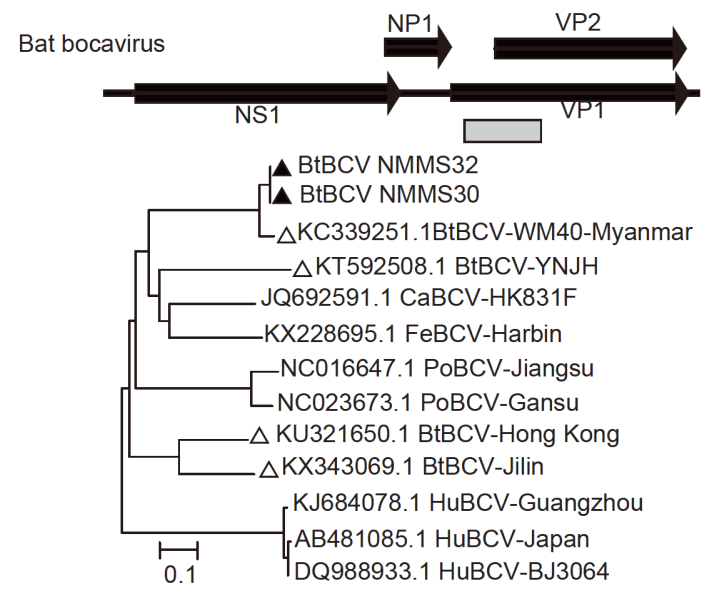

Rotavirus A

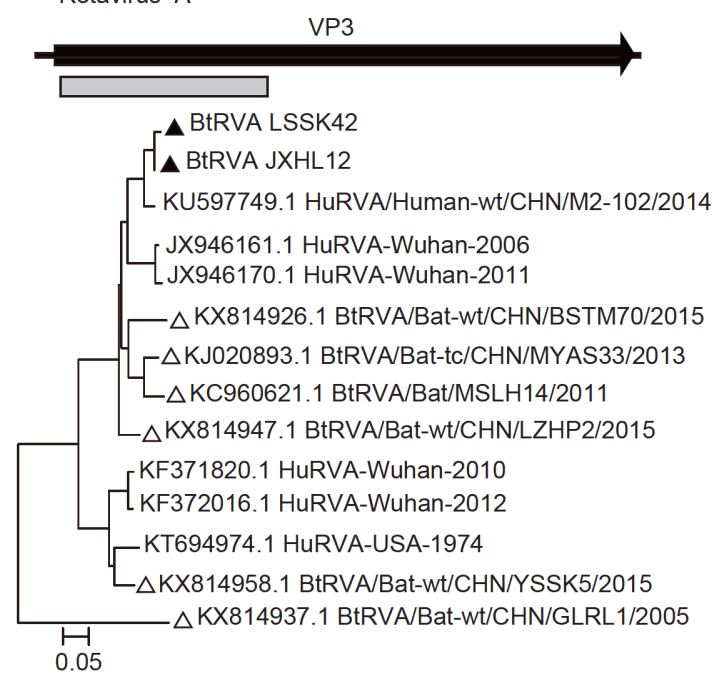

图 3 蝙蝠肝炎病毒 $(\mathrm{A})$ 、博卡病毒(B)和A型轮状病毒(C)检测片段的进化分析，以及这些检测片段(灰色框)在参考基因上的 位置. 用于进化分析的检测片段大小分别为 $416 \mathrm{bp}$ (蝙蝠肝炎病毒)、 $620 \mathrm{bp}$ (博卡病毒)、836 bp(A型轮状病毒). 本研究得到的 检测片段用黑三角指示, 其他蝙蝠病毒用白三角指示, 在BtHBV的进化树中, 病毒代表种用加粗斜体表示

Figure 3 Phylogenetic analyses of amplicons of bat hepatitis virus (A), bocavirus (B) and group A rotavirus (C). Those amplicons (grey boxes) are mapped against reference sequences to show their position. The length of amplicons used in phylogenetic analyses are 416 bp (bat hepatitis virus), $620 \mathrm{bp}$ (bocavirus) and $836 \mathrm{bp}$ (group A rotavirus ) respectively. In phylogenetic trees, amplicons obtained here are highlighted with filled triangles and other bat-related viruses with open triangles, the prototypes of viral species in BtHBV tree are illustrated in bold italics

\section{BtBCV-YNJH同源性仅为54.4\%(图3B).}

A型轮状病毒. A型轮状病毒(group A rotavirus, $\mathrm{RVA}$ ) 是婴幼儿腹泻最为重要的病毒性病原体, 同时也 是经济动物常见的腹泻病因之一 ${ }^{[24]}$. 本研究获得 8 条 RVA的reads，拼接后获得 1 条 contig. 运用本实验室建 立的检测方法对所有的样品进行检测 ${ }^{[21]}$, 引物及扩增 片段信息见表 2 , 结果从灵山县小黄蝠的肠道组织中 和靖西市中蹄蝠的肠道组织共检测到 2 株蝙蝠轮状病 毒(bat RVA，BtRVA)(表1)，命名为BtRVA LSSK42和
JXHL12, 彼此之间核甘酸同源性为 $99.3 \%$. 多序列比对 和进化分析显示, 这两株病毒与 2014年在广西造成幼 儿腹泻的人的轮状病毒RVA/Human-wt/CHN/M2-102/ 2014 形成一个进化分支 ${ }^{[25]}$, 同源性分别为 $95.4 \%$ 和 $96.1 \%$; 与该地区其他蝙蝠源轮状病毒进行比较, 发现 这两个病毒的扩增片段与广西百色的BSTM70和鹿寨 的LZHP2 以及云南预远的MYAS33和芒市的MSLH14 同源性 $85.7 \% \sim 89.8 \%$ (图3C).

星状病毒. 星状病毒(astrovirus, AstV)为单股正链 


\section{表 2 病毒PCR检测引物信息表}

Table 2 primers information of virus detection by PCR

\begin{tabular}{|c|c|c|c|c|c|}
\hline 检测病毒 & 引物名称 & 引物序列 & 基因 & 扩增片段大小 & 参考文献 \\
\hline \multirow{2}{*}{ hepadnavirus } & $>$ OHVFP & TSGTGGTGGAYTTCTCTC & \multirow{2}{*}{ S gene } & \multirow{2}{*}{$416 \mathrm{bp}$} & \multirow[t]{2}{*}[19]{} \\
\hline & $>$ OHVRP & ACTGAGCCARGAGAAWYG & & & \\
\hline \multirow{4}{*}{ bocavirus } & $>$ BK-FP1 & GTCAWAAATGTDRTTACTGGGA & \multirow{4}{*}{ VP1 gene } & \multirow{4}{*}{$620 \mathrm{bp}$} & {$[20]$} \\
\hline & $>$ BK-FP2 & ATHAABAAAGGTGAAAATCCRTA & & & \\
\hline & $>\mathrm{BK}-\mathrm{RP} 1$ & TYATAKGGAAGTTCTGGCA & & & \\
\hline & $>\mathrm{BK}-\mathrm{RP} 2$ & CCAGTCTTGTGGTGAAAAYTG & & & \\
\hline \multirow{3}{*}{ group a rotavirus } & >VP3F1 & TTTAAGACRYRGTRTGGCTC & \multirow{3}{*}{ VP3 gene } & \multirow{3}{*}{$836 \mathrm{bp}$} & {$[21]$} \\
\hline & $>$ VP3F2 & GTGGCTCARGTRTATGCAG & & & \\
\hline & $>\mathrm{VP} 3 \mathrm{R}$ & TRHATCCARTAHGADGGIGC & & & \\
\hline \multirow{5}{*}{ astrovirus } & >ASV-F1-1 & GARTTYGATTGGRCKCGKTAYGA & \multirow{5}{*}{ RdRp gene } & \multirow{5}{*}{$422 \mathrm{bp}$} & {$[20]$} \\
\hline & >ASV-F1-2 & GARTTYGATTGGRCKAGGTAYGA & & & \\
\hline & >ASV-F2-1 & CGKTAYGATGGKACKATHCC & & & \\
\hline & $>$ ASV-F2-2 & AGGTAYGATGGKACKATHCC & & & \\
\hline & $>$ ASV-R & GGYTTKACCCACATNCCRAA & & & \\
\hline \multirow{9}{*}{ rhabdovirus } & >Lyssa-F1-1 & BGAYYTVATHATHGGNYTNAARCC & \multirow{9}{*}{ L gene } & \multirow{9}{*}{$262 \mathrm{bp}$} & {$[22]$} \\
\hline & $>$ Lyssa-F1-2 & ATCTCTAATTATCGGCTTGAAACC & & & \\
\hline & $>$ Lyssa-F1-3 & AGAATTGGTGATTGGCCTCAAGGC & & & \\
\hline & $>$ Lyssa-F2-1 & THGGHYTVAARCCVAARGARMGRG & & & \\
\hline & $>$ Lyssa-F2-2 & TCGGCTTGAAACCGAAAGAAAGAG & & & \\
\hline & $>$ Lyssa-F2-3 & TTGGCCTCAAGGCAAAAGAACGCG & & & \\
\hline & >Lyssa-R-1 & RTGRTTRTTCCAYTTYTCRTARTC & & & \\
\hline & >Lyssa-R-2 & ATGCCAGTTCCATTTTTCGTAATC & & & \\
\hline & >Lyssa-R-3 & ATGAGCATTCCATTTTTCATAGTC & & & \\
\hline \multirow{4}{*}{ coronavirus } & $>\operatorname{cov} \mathrm{F} 1$ & ATGGGWTGGGAYTAYCCIAARTG & \multirow{4}{*}{ ORF1b(RdRp) } & \multirow{4}{*}{$440 \mathrm{bp}$} & [23] \\
\hline & $>\operatorname{cov} \mathrm{R} 1$ & TGYTGIGARCAAAAYTCRTG & & & \\
\hline & $>\operatorname{cov} \mathrm{F} 2$ & GGITGGGAYTAYCCIAARTGYGA & & & \\
\hline & $>\operatorname{cov} \mathrm{R} 2$ & CCRTCATCWGAIARWATCATCAT & & & \\
\hline
\end{tabular}

RNA病毒, 基因组大小为6.4 7.7 kb(https://talk.ictvonline.org/taxonomy/), 本研究共获得AstV 的reads非常丰 富, 有20671条, 经过初步拼接后获得175条星状病毒 contigs, 长度为200 400 bp, 初步分析显示这些contigs 彼此间同源性较低. 运用本实验室建立的检测方法对

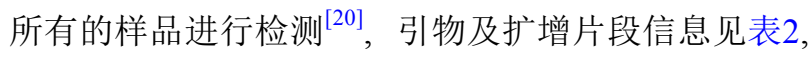
结果从桂越地区7个采样点采集的蝙蝠中共检测到 27 株蝙蝠 $\mathrm{AstV}$ (bat AstV, BtAstV)，总体阳性率为 $10.1 \%$ (27/268), 具体检测结果可见表1. 将检测片段与当前已 知 AstV 代表种进行多序列比对和进化分析, 结果发现 本研究的 $A s t V$ 呈现出丰富的遗传多样性, 可以分为7
个进化分支(图4A), 其中分支1包含来自于灵山的小黄 蝠、宁明的普通长翼蝠、安宁的中蹄蝠和托氏菊头蝠 以及皮氏菊头蝠、靖西的中蹄蝠和丑蹄蝠、防城的中 菊头蝠的 14 个毒株. 在此分支中, 除了 JXHL12 以外, 其 余 13 个毒株同源性彼此高达 $92.8 \% \sim 100.0 \%$, 它们与 $\mathrm{Hil} / \mathrm{GX} / \mathrm{bazt} 12$ 的同源性最高为 $92.8 \% \sim 100.0 \%$, 而与 JXHL12同源性为 $74.3 \% \sim 76.6 \%$; 分支 2 包含一个来自 宁明普通长翼蝠NMMS28, 它与ICTV收录的新种代表 株AFCD 57 同源性为 $71.6 \%$; 分支3包含了来自东兴普 通长翼蝠和中蹄蝠以及中菊头蝠、龙州黒髦墓蝠的 4 个毒株, 彼此间同源性为 $75.1 \%$ 99.3\%, 该分支比较特 
殊，它们与啮齿动物源的 GD2015毒株和猪源的 GXWZ18毒株形成了一个进化分支，且LZTM16与 GXWZ18的同源性高达 $92.3 \%$; 分支4只有来自宁明普 通长翼蝠的NMMS33, 它与AFCD68的同源性最高为 $82.3 \%$; 分支 5 包含了 5 个毒株, 来自于防城的中菊头蝠 和中蹄蝠、东兴的中菊头蝠、靖西的丑蹄蝠和安宁的 大蹄蝠，该分支具有比较丰富的遗传多样性，彼此间为 $73.1 \% \sim 99.8 \%$, 且与此分支其他BtAstV 同源性为 $70.6 \%$ $\sim 81.8 \%$; 分支6包括一株来自东兴中菊头蝠的DXRA19 和猪源星状病毒PoAstV 5-JPN, 其同源性为 $91.8 \%$; 而 来自灵山小黄蝠的LSSK39形成了分支7，该毒株与当 前所有 $A s t V$ 具有很远的进化关系，仅与KSA-239同源 性为 $32.4 \%$ (图4A).

弹状病毒. 弹状病毒(rhabdovirus, RV)属于单股负 链RNA病毒, 基因组大小约为 $12 \mathrm{~kb}$, 依次编码核衣壳 蛋白 $(\mathrm{N})$ 、磷蛋白 $(\mathrm{P})$ 、基质蛋白 $(\mathrm{M})$ 、糖蛋白 $(\mathrm{G})$ 和聚 合酶蛋白(L)(图4B)(https://talk.ictvonline.org/taxonomy/). 运用本实验室建立的检测方法对所有的样品进 行检测 ${ }^{[22]}$, 引物及扩增片段信息见表2, 结果从靖西市 禄峒镇的大蹄蝠和丑蹄蝠肠道组织中共检测到 2 株弹 状病毒, 分别命名为Bat RV (BtRV) JXHA4和JXHT18, 从灵山县小黄蝠肠道组织中检测到6株弹状病毒, 分别 命名为BtRV LSSK2, LSSK7, LSSK8, LSSK9, LSSK15 和LSSK33(表1)。进化分析和多序列比对，发现这8株 弹状病毒形成两个不同的进化分支，分支间的同源性 为 $26.5 \%$ 34.6\%(图4B), 而分支内同源性分别为 $93.8 \%$ $\sim 98.5 \%$ (分支1)和 $84.2 \% \sim 91.2 \%$ (分支 2 ), 其中分支 1 包 含了JXHT18, JXHA4, LSSK15, LSSK33和LSSK2, 与 蝙蝠源的SX2013病毒同源性较近，但同源性也仅为 $57.3 \%$. 而分支 2 形成了独立的外群，与当前所有弹状 病毒同源性较远, 最高仅为 $33.8 \%$ (图4B).

冠状病毒. 冠状病毒(coronavirus, CoV) 是当前最 大的RNA病毒, 本研究共获得 $\mathrm{CoV}$ 的reads有 4482条, 经过拼接后获得76条重叠序列, 长度为300 3600 bp. 运用本实验室建立的检测方法对所有的样品进行检 测 ${ }^{[23]}$, 引物及扩增片段信息见表2, 结果从灵山县小黄 蝠肠道组织中检测出6株蝙蝠冠状病毒 (bat $\mathrm{CoV}$, $\mathrm{BtCoV})$, 阳性率为 $14 \%(6 / 43)$; 从防城区中菊头蝠的肠 道组织中检测出 3 株 BtCoV, 阳性率为 $15 \%(3 / 30)$ (表 1$)$. 这9株 $\mathrm{BtCoV}$ 可以分为 3 个进化分支(图4C), 分支之间 的同源性为 $68.3 \% \sim 72.1 \%$. 分支 1 包括 6 个毒株, 都是来
自于灵山小黄蝠，其中LSSK38与其他5株(彼此 $94.8 \%$ $\sim 99.8 \%$ 同源性)不同，同源性为 $82.2 \% \sim 86.4 \%$, 它们与 $\mathrm{BtCoV} 512$ 的同源性最高为 $85.2 \% \sim 98.8 \%$; 分支2包括 两株来自于防城的中菊头蝠FCRA31和FCRA38, 它们 彼此同源性很高，达到了 $99.3 \%$, 而与该分支的HKU10 同源性为最高为 $81.0 \%$; 另外一株来自于防城的中菊 头蝠FCRA23形成了分支 3 , 它与 HKU2 以及猪源的 SADS CoV同源性均为 $94.8 \%$ (图4C).

\section{3 讨论}

蝙蝠因能携带多种人兽共患病毒而备受关注，而 已有的经历也明确指出很多蝙蝠病毒能造成人和其他 动物的疫病暴发, 防范蝙蝠源新发传染病的出现, 已经 成为公共卫生领域里的一个研究热点 ${ }^{[26]}$. 得益于高通 量测序技术的发展, 以病毒宏基因组学技术为代表的 新一代病原生态学研究方法在蝙蝠病毒的研究中取得 了巨大的成绩，使得近 10 年来所发现的蝙蝠病毒远远 超过过去所有发现的蝙蝠病毒，这些提前发现的蝙蝠 病毒极大地加深了人们对蝙蝠病毒多样性的认识，也 为防范新发传染病和病毒快速溯源提供了重要的参 考 ${ }^{[20,27,28]}$, 其典型的案例, 如2017年广东规模化猪场发 生的不明原因的急性腹泻，结果发现其病原体为当地 蝙蝠携带的冠状病毒HKU2 ${ }^{[29]}$. 本研究通过病毒宏基 因组学对桂越边境地区蝙蝠携带病毒进行全面解析, 结果揭示了非常丰富的病毒信息, 其中不乏一些人兽 共患病原体, 如汉坦病毒、 $\mathrm{A}$ 型轮状病毒等, 这充分说 明蝙蝠病毒仍然是该地区一种潜在的公共卫生威胁, 未来仍需进行长期的实时监测.

本研究对4种病毒宏基因组学所发现的病毒reads 进行组装, 并对其进行进化分析, 结果初步揭示了这 4 种病毒的遗传多样性. PBV分布广泛, 宿主范围涉及爬 行动物、禽类、人和其他哺乳动物等，该病毒的致病 性尚不明确，但调查表明PBV可能导致人和其他哺乳 动物腹江 ${ }^{[30,31]}$, 虽然国际病毒分类委员会(International Committee on Taxonomy of Viruses, ICTV)仅收录1属2 种小双节RNA病毒(human picobirnavirus和rabbit picobirnavirus), 但随着更多PBV的发现，丰富的遗传多样 性使得很多PBV可能成为新的病毒种(https://talk.ictvonline.org/taxonomy/). 本研究组装的两条contigs几乎 涵盖了PBV S2片段的全长(图2A), 这两个contigs的同 


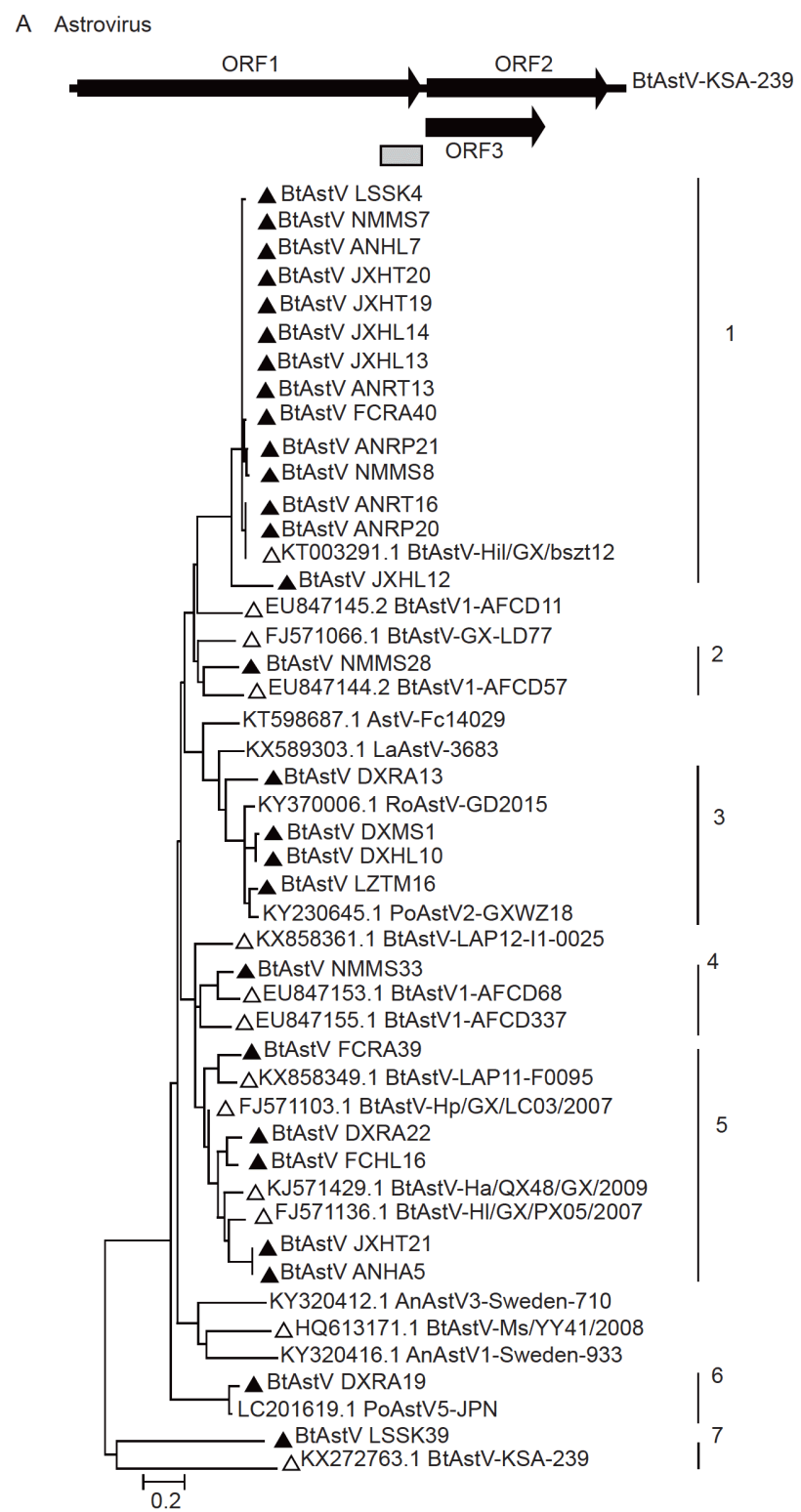

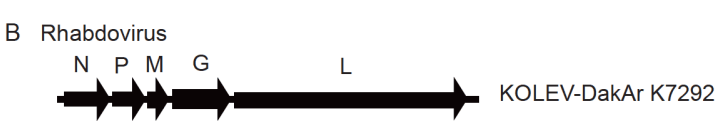
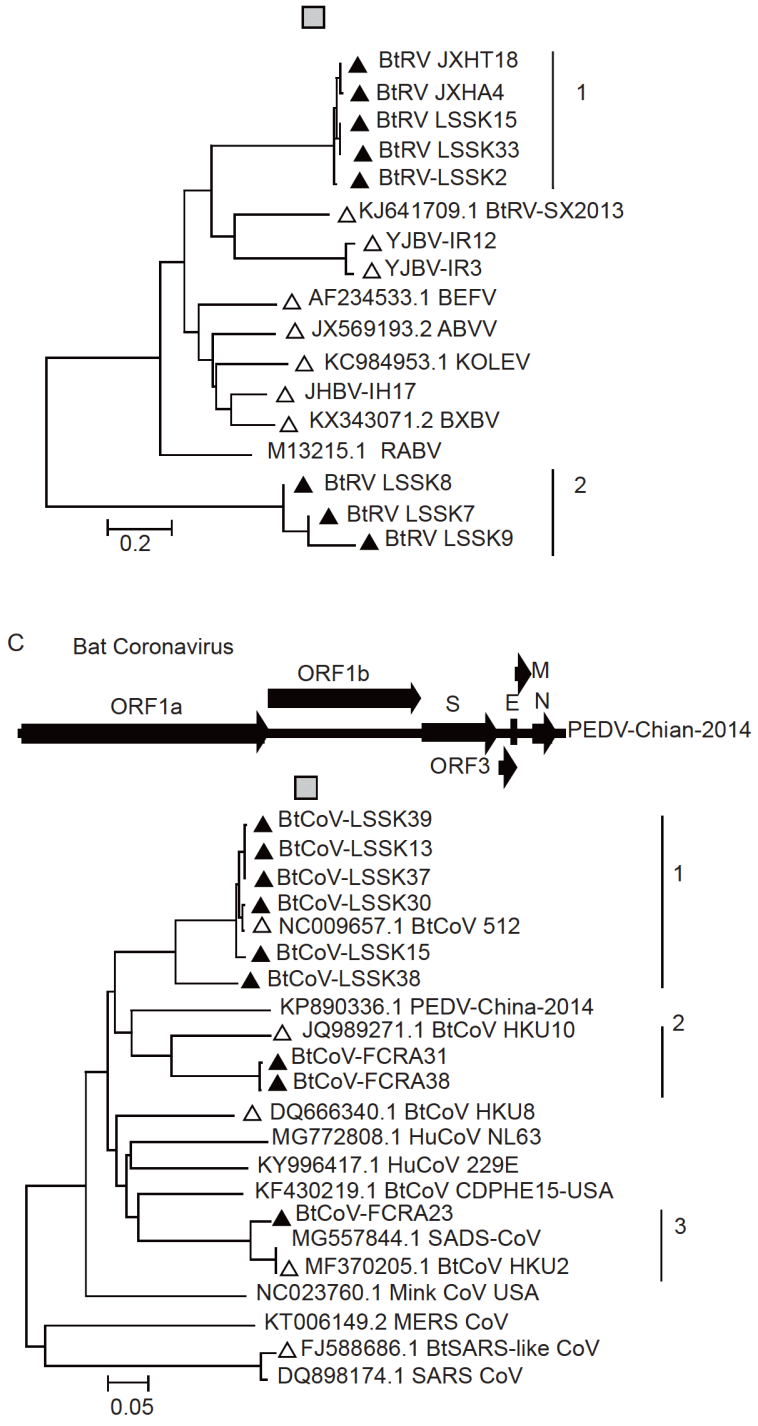

图 4 星状病毒(A)、弹状病毒(B)和冠状病毒(C)检测片段的进化分析, 以及这些检测片段(灰色框)在参考基因上的位置. 用于 进化分析的检测片段大小分别为 $422 \mathrm{bp}$ (星状病毒)、 $262 \mathrm{bp}$ (弹状病毒)、 $440 \mathrm{bp}$ (冠状病毒). 本研究得到的检测片段用黑三角 指示, 其他蝙蝠病毒用白三角指示; 在进化树中, 病毒代表种用加粗斜体显示

Figure 4 Phylogenetic analyses of amplicons of astrovirus (A), rhabdovirus (B) and coronavirus (C). Those amplicons (grey boxes) are mapped against reference sequences to show their position. The length of amplicons used in phylogenetic analyses are 422 bp (astrovirus), 262 bp (rhabdovirus) and $440 \mathrm{bp}$ (coronavirus) respectively. In phylogenetic trees, amplicons obtained here are highlighted with filled triangles and other bat-related viruses with open triangles, and prototypes of viral species are illustrated in bold italics.

源性也足以说明它们来自两个不同的病毒，同时与当 前已知病毒具有很大的差异性，也进一步说明该地区 蝙蝠群体中至少存在两种新型PBV. 目前ICTV收录5 属7种CV, 其中多个成员具有明显的致病性, 如诺如病 毒(noroviruses，NoVs)是导致人类急性暴发性胃肠炎
的常见病原体之一 ${ }^{[32]}$. 和PBV类似, 本研究组装得到 的两条 CV contigs彼此间具有显著的差异性，同时与 其他已知 $\mathrm{CV}$ 的同源性也低于 $58.5 \%$, 使其足以成为两 种不同的新型 $\mathrm{CV}$. 本研究组装的 $\mathrm{PyV}$ 和 $\mathrm{HCV}$ 都只有 一条contig, PyV与其他蝙蝠源PyV形成了一个非常 
独立的进化分支，提示该群PyV可能与宿主呈现出一 定的共进化特征；而该地区的HCV与其他HCV 的同 源性也说明 HCV 在蝙蝠群体中具有很丰富的遗传多 样性.

根据病毒宏基因组揭示的结果, 本研究对 6 种病毒 进行了系统的检测. 从病毒种类来看, 该地区蝙蝠携带 AstV 具有一定的普遍性，出现在了每个检测点和多个 蝙蝠品种中(表1); 而其余病毒则体现出一定的地域特 点和宿主特异性，尤其是BCV和BtHBV仅出现在一个 地方的一种蝙蝠中; 从蝙蝠种类来看，小黄蝠携带有 AstV, CoV, RVA和RV 4种检测病毒, 而其他蝙蝠所携 带的检测病毒都不超过 2 种, 说明小黄蝠具有复杂的病 毒本底. 嗜肝DNA病毒科目前包含两个属，分别是感 染禽类的禽嗜肝DNA病毒属(Avihepadnavirus)和感染 哺乳动物的正嗜肝DNA病毒属(Orthohepadnavirus) ${ }^{[33]}$, 其成员一直比较稳定，直到近年来大量的BtHBV 被发 现，其收录的种由2013年的6种增加到现在的14种，其 中蝙蝠源病毒就有4种, 事实上还有多种全新的蝙蝠嗜 肝DNA病毒尚未被ICTV收录为新种，本实验室Yang 等人 ${ }^{[34]}$ 通过系统分析后，发现目前所有蝙蝠源嗜肝 DNA病毒(bat hepatitis B virus, BtHBV)可以划分为7 个种, 其中源自我国的BtHBV 7又可以进一步分为 6 个 基因型, 说明BtHBV复杂的遗传多样性. 本研究发现的 BtHBV与当前已知病毒有一定的差异，虽然不足以成 为病毒新种 $(80 \%$ 的核苷酸同源性), 但这种遗传差异 可能使其成为新的基因型，这进一步证明BtHBV在我 国蝙蝠中的遗传多样性; 值得注意的是, 虽然都是从 广西蝙蝠中发现，DXRA22与其他广西病毒并未形成 更近的进化分支，反而与发现地方更远的贵州和河南 蝙蝠病毒具有相对更近的进化关系，这体现出BtHBV 在我国蝙蝠中复杂的进化历史. $\mathrm{BCV}$ 能导致免疫低下 患者的腹泻, 该病毒也是一种比较常见的蝙蝠病毒 ${ }^{[35]}$, 本研究发现的两株 BCV, 相对于发现地点更近的云南 蝙蝠病毒YNJH, 与缅甸蝙蝠发现的WM40具有显著更 近的进化关系，这主要是由于这两株病毒与WM40都 是从长翼蝠中发现的 ${ }^{[20]}$, 而 $\mathrm{YNJH}$ 是从三叶蹄蝠中发 现的 ${ }^{[36]}$, 说明 BCV 的进化与宿主具有一定的关系. RVA的宿主范围广泛，几乎所有哺乳动物都能找到该 病毒的痕迹，甚至能感染鸟类 ${ }^{[37]}$. 首个BtRVA是 2010 年在非洲黄毛果蝠体内发现 ${ }^{[38]}$; 随后本实验室在我国 南方BtRVA开展了系统的流行病学研究, 发现并分离
了多株BtRVA ${ }^{[39,40]}$, 最终确定蝙蝠也是轮状病毒的自 然宿主之一, 我国南方蝙蝠流行的轮状病毒高度类似, 并命名为MLSH14-like轮状病毒，同时发现广西的一 株BtRVA LZHP2传播给人并造成腹江，最终总结出蝙 蝠在我国南方轮状病毒的跨种传播和基因重排中处于 “中转站”的位置 ${ }^{[22]}$. 本研究从两个地方不同的蝙蝠中 发现了高度同源的RVA, 并且相对于其他广西BtRVA 而言，与人源M2-102的同源性更近，这不仅说明该病 毒能在不同蝙蝠种中传播，也进一步印证BtRVA能夸 种传播到人或与人源RVA发生基因的重排.

AstV属于星状病毒科(Astroviridae)，其部分成员 能导致儿童腹泻, 也会影响肠道微生物的菌落 ${ }^{[41]}$, 研 究表明蝙蝠携带多种星状病毒, 并且其核苷酸具有一 定的差异性，这表明蝙蝠源星状病毒具有遗传多样 性 ${ }^{[42,43]}$. 本研究所发现的 $\mathrm{AstV}$, 除了是分布最广的病 毒以外, 也是极具遗传多样性的病毒, 能分为 7 个进化 分支，其中多个分支(如分支1，3和5)包含有来自不同 地方、不同蝙蝠种类的病毒，尤其是分支1中不同地 方不同蝙蝠携带的 $\mathrm{AstV}$ 同源性高达 $92.8 \%$ 以上，说明 星状病毒在能在不同蝙蝠种间夸种传播; 然而多个分 支的BtAstV与其他动物源的 $A s t V$ 具有很近的进化关 系，如分支3中BtAstV与啮齿动物 $A s t V$ GD2015和猪 AstV GXWZ18、分支6中BtAstV与猪AstV JPN, 则说 明星状病毒在蝙蝠和其他动物之间的跨种传播. RV宿 主范围广泛，能够感染哺乳动物、鸟类、鱼类、节肢 动物以及植物, 蝙蝠源的 RV 具有非常复杂的遗传多样 性, 分属于狂犬病毒属、水疮性口炎病毒属和Ledantevirus属，其中蝙蝠源狂犬病毒是美国狂犬病毒病的主 要元凶 ${ }^{[44]}$, 本课题组 ${ }^{[24]}$ 也曾系统调查了东北和华南地 区蝙蝠弹状病毒的遗传多样性，发现广东广西蝙蝠群 体中存在一群高度特异的弹状病毒(Yangjiang bat virus, YJBV), 可能是一个全新的病毒属. 本研究所发 现的新型BtRV与 $Y J B V$ 具有显著的差异性，同时分为 两个进化分支, 这也进一步增加了 $\mathrm{RV}$ 遗传多样性; 和 YJBV一样, 这两个进化分支, 尤其是分支 2 , 与当前已 知病毒的遗传差异, 足以使其成为新的病毒属的代表 成员. 目前 ICTV共收录4属30种 $\mathrm{CoV}$, 其中多种成员对 人和其他动物具有严重的致病性, 如 SARS冠状病 毒 $^{[45]} 、$ MERS冠状病毒 ${ }^{[46]}$ 、猪流行性腹泻病毒 ${ }^{[47]}$ 等. 大量调查表明 $\mathrm{BtCoV}$ 主要是Alphacoronavirus和Betacoronavirus，并且蝙蝠病毒可能是这两个病毒属的祖 
先病毒和基因来源 ${ }^{[48]}$. 本研究发现的 $\mathrm{BtCoV}$ 与 $\mathrm{CoV}$ 代 表种具有较近的进化关系, 因此都不属于 $\mathrm{CoV}$ 新种, 虽然这些 $\mathrm{BtCoV}$ 分为了 3 个进化分支, 但每个分支的成 员都来自于同一地方的同一种蝙蝠，说明 $\mathrm{CoV}$ 在不同 蝙蝠种中具有一定的宿主偏好性; 值得注意的是, 分 支3中的FCRA23与新发现的猪急性腹泻病原体的 HKU2或者SADS CoV具有很高的同源性, 提示防城港 地区养猪业也面临着该病毒的威胁.

本研究通过病毒宏基因组学方法系统获得了桂越
边境地区蝙蝠携带病毒的病原本底数据，同时对部分 病毒进行了系统的检测和进化分析, 为掌握该地区蝙 蝠携带病毒的多样性提供了重要的基础数据. 本研究 发现了多种新型病毒, 但由于这些分析都是基于部分 检测片段, 仅此未来需要通过全基因分析以进一步明 确它们的进化地位. 本研究的采样点紧靠桂越边境线, 蝙蝠的飞翔能力使其很容易进行跨境迁徙, 因此对该 地区蝙蝠病毒的研究也有助于监测周边国家蝙蝠病毒 的本底情况.

\section{参考文献}

1 Fenton M B S, Nancy B. Bats: A World of Science and Mystery. Chicago: University of Chicago Press, 2014

2 Jiang Z, Liu S, Wu Y, et al. China's mammal diversity (2nd edition). Biodiv Sci, 2017, 25: 886-895

3 Moratelli R, Calisher C H. Bats and zoonotic viruses: can we confidently link bats with emerging deadly viruses? Mem Inst Oswaldo Cruz, 2015, 110: $1-22$

4 Towner J S, Pourrut X, Albariño C G, et al. Marburg virus infection detected in a common African bat. PLoS ONE, 2007, 2: e764

5 Olival K J, Islam A, Yu M, et al. Ebola virus antibodies in fruit bats, bangladesh. Emerg Infect Dis, 2013, 19: 270-273

6 Pulliam J R C, Epstein J H, Dushoff J, et al. Agricultural intensification, priming for persistence and the emergence of Nipah virus: a lethal batborne zoonosis. J R Soc Interface, 2012, 9: 89-101

7 Field H E. Evidence of Australian bat lyssavirus infection in diverse Australian bat taxa. Zoon Public Health, 2018, 65: 742-748

8 Ge X Y, Li J L, Yang X L, et al. Isolation and characterization of a bat SARS-like coronavirus that uses the ACE2 receptor. Nature, 2013, 503: $535-538$

9 Luby S P. The pandemic potential of Nipah virus. Antiv Res, 2013, 100: 38-43

10 Chua K B, Wang L F, Lam S K, et al. Full length genome sequence of Tioman virus, a novel paramyxovirus in the genus Rubulavirus isolated from fruit bats in Malaysia. Arch Virol, 2002, 147: 1323-1348

11 Watanabe S, Ueda N, Iha K, et al. Detection of a new bat gammaherpesvirus in the Philippines. Virus Genes, 2009, 39: 90-93

12 Tsuda S, Watanabe S, Masangkay J S, et al. Genomic and serological detection of bat coronavirus from bats in the Philippines. Arch Virol, 2012, 157: 2349-2355

13 Kobayashi S, Sasaki M, Nakao R, et al. Detection of novel polyomaviruses in fruit bats in Indonesia. Arch Virol, 2015, 160: 1075-1082

14 Arai S, Nguyen S T, Boldgiv B, et al. Novel bat-borne hantavirus, Vietnam. Emerg Infect Dis, 2013, 19: 1159-1161

15 Sun K, Feng J, Zhang Z, et al. Cryptic diversity in Chinese rhinolophids and hipposiderids (Chiroptera: Rhinolophidae and Hipposideridae). Mammalia, 2009, 73

16 Kunz A F, Possatti F, de Freitas J A, et al. High detection rate and genetic diversity of picobirnavirus in a sheep flock in Brazil. Virus Res, 2018, 255: $10-13$

17 Raza S A, Clifford G M, Franceschi S. Worldwide variation in the relative importance of hepatitis B and hepatitis C viruses in hepatocellular carcinoma: a systematic review. Br J Cancer, 2007, 96: 1127-1134

18 Zou L, Zhang W, Ruan S. Modeling the transmission dynamics and control of hepatitis B virus in China. J Theor Biol, 2017, 262: 330-338

19 He B, Fan Q, Yang F, et al. Hepatitis virus in long-fingered bats, Myanmar. Emerg Infect Dis, 2013, 19: 638-640

$20 \mathrm{He}$ B, Li Z, Yang F, et al. Virome profiling of bats from Myanmar by metagenomic analysis of tissue samples reveals more novel Mammalian viruses. PLoS ONE, 2013, 8: e61950

21 He B, Yang F, Yang W, et al. Characterization of a novel G3P[3] rotavirus isolated from a lesser horseshoe bat: a distant relative of feline/canine rotaviruses. J Virol, 2013, 87: 12357-12366

22 Xu L, Wu J, Jiang T, et al. Molecular detection and sequence characterization of diverse rhabdoviruses in bats, China. Virus Res, 2018, 244: 208- 
212

$23 \mathrm{He} \mathrm{B}$, Zhang Y, Xu L, et al. Identification of diverse alphacoronaviruses and genomic characterization of a novel severe acute respiratory syndrome-like coronavirus from bats in China. J Virol, 2014, 88: 7070-7082

24 Kiseleva V, Faizuloev E, Meskina E, et al. Molecular-genetic characterization of human rotavirus A strains circulating in Moscow, Russia (20092014). Virol Sin, 2018, 33: 304-313

25 Dong H, Qian Y, Nong Y, et al. Genomic characterization of an unusual human G3P[3] rotavirus with multiple cross-species reassortment. Chin J Virol, 2016, 32: 129-140

26 Shi Z. Bat and virus. Protein Cell, 2010, 1: 109-114

27 Ge X, Li Y, Yang X, et al. Metagenomic analysis of viruses from bat fecal samples reveals many novel viruses in insectivorous bats in China. J Virol, 2012, 86: 4620-4630

28 Wu Z, Ren X, Yang L, et al. Virome analysis for identification of novel mammalian viruses in bat species from Chinese provinces. J Virol, 2012, 86: 10999-11012

29 Zhou P, Fan H, Lan T, et al. Fatal swine acute diarrhoea syndrome caused by an HKU2-related coronavirus of bat origin. Nature, 2018, 556: 255258

30 van Leeuwen M, Williams M M W, Koraka P, et al. Human picobirnaviruses identified by molecular screening of diarrhea samples. J Clin Microbiol, 2010, 48: 1787-1794

31 Giordano M O, Martinez L C, Rinaldi D, et al. Detection of picobirnavirus in HIV-infected patients with diarrhea in Argentina. J Acquired Immun Def Syn Human Retrovirol, 1998, 18: 380-383

32 Yang L, Wang Q, Xu L, et al. Detection and characterization of a novel norovirus in bats, China. Virol Sin, 2018, 33: 100-103

33 Dill J A, Camus A C, Leary J H, et al. Distinct viral lineages from fish and amphibians reveal the complex evolutionary history of hepadnaviruses. J Virol, 2016, 90: 7920-7933

34 Yang L, Wu J, Hu T, et al. Genetic diversity of bat orthohepadnaviruses in China and a proposed new nomenclature. Infection Genets Evol, 2018, 63: $135-143$

35 Zhang H L, Zhang F Q, Hu T S, et al. Research progress on natural infection of bat with zoonosis-related viral pathogens in Yunnan Province, China. Chin J Zoon, 2017, 33: 821-827

36 Li X Y, Chen G, Xia L L, et al. Detection and identification of a new bat bocavirus species in Yunnan. Military Med Sci, 2016, 40: 207-212+233 Deol P, Kattoor J J, Sircar S, et al. Avian group D rotaviruses: structure, epidemiology, diagnosis, and perspectives on future research challenges. Pathogens, 2017, 6: 53

38 Esona M D, Mijatovic-Rustempasic S, Conrardy C, et al. Reassortant group a rotavirus from straw-colored fruit bat (Eidolon helvum ). Emerg Infect Dis, 2010, 16: 1844-1852

39 Xia L, Fan Q, He B, et al. The complete genome sequence of a G3P[10] Chinese bat rotavirus suggests multiple bat rotavirus inter-host species transmission events. Infection Genets Evol, 2014, 28: 1-4

40 He B, Huang X, Zhang F, et al. Group A rotaviruses in Chinese bats: genetic composition, serology, and evidence for bat-to-human transmission and reassortment. J Virol, 2017, 91: e02493-e02516

41 Wasimuddin, Brändel S D, Tschapka M, et al. Astrovirus infections induce age-dependent dysbiosis in gut microbiomes of bats. ISME J, 2018, 12: $2883-2893$

42 Zhu H C, Chu D K W, Liu W, et al. Detection of diverse astroviruses from bats in China. J Gen Virol, 2009, 90: 883-887

43 Xiao J, Li J, Hu G, et al. Isolation and phylogenetic characterization of bat astroviruses in southern China. Arch Virol, 2011, 156: 1415-1423

44 Calisher C H, Childs J E, Field H E, et al. Bats: important reservoir hosts of emerging viruses. Clin Microbiol Rev, 2006, 19: 531-545

45 Li W, Shi Z, Yu M, et al. Bats are natural reservoirs of SARS-like coronaviruses. Science, 2005, 310: 676-679

46 Yin Y, Wunderink R G. MERS, SARS and other coronaviruses as causes of pneumonia. Respirology, 2018, 23: 130-137

47 Fan B, Jiao D, Zhao X, et al. Characterization of chinese porcine epidemic diarrhea virus with novel insertions and deletions in genome. Sci Rep, 2017, 7: 44209-44219

48 Woo P C Y, Lau S K P, Lam C S F, et al. Discovery of seven novel mammalian and avian coronaviruses in the genus deltacoronavirus supports bat coronaviruses as the gene source of alphacoronavirus and betacoronavirus and avian coronaviruses as the gene source of gammacoronavirus and deltacoronavirus. J Virol, 2012, 86: 3995-4008 


\title{
Metagenomic analysis of bat virome in the Guangxi-Vietnam border area
}

\author{
YAN Chao ${ }^{1,2}$, ZHANG Chang ${ }^{2}, \mathrm{XU}_{\mathrm{Lin}^{2}}{ }^{2}, \mathrm{MENG} \mathrm{Fei}^{3}$, WU JianMin ${ }^{3}$, TU ChangChun ${ }^{2}$, LI Yong ${ }^{1}$ \\ $\&$ HE Biao ${ }^{2}$ \\ 1 School of Life Science, NingXia University, Yinchuan 750021, China; \\ 2 Key Laboratory of Jilin Province for Zoonosis Prevention and Control, Military Veterinary Institute, Academy of Military Medical Sciences, \\ Changchun 130122, China; \\ 3 Guangxi Veterinary Research Institute, Nanning 530001, China
}

The areas covering Guangxi, China and Vietnam have greatly and geographically strategic importance. These areas have abundant bat resources with many harboring diverse zoonotic viruses. In order to monitor the cross-border transmission of bat viruses in the Guangxi-Vietnam border area and to prevent potential emerging infectious diseases caused by bat viruses, understanding the bat virus diversity and their evolution are greatly necessary. Here we conducted viral metagenomic analysis of bats sampled in the border area, and results revealed 49 families of viruses, including those infecting vertebrate, plants, insects and bacteria. Additionally, we screened hepadnavirus, bocaparvovirus, group A rotavirus, astrovirus, rhabdovirus and coronavirus in those bat samples, and phylogenetically analyzed those amplicons. Results showed that astroviruses were widely present in those animals with great genetic diversity, but other viruses were only detected in some specific bats. Bocaparvoviruses and rhabdoviruses were significantly divergent from currently known viruses, and possibly were prototypes of new species. Notably, group A viruses identified here shared high identity with a human virus, suggestive of inter-species transmission and reassortment. The present study profiled the viromic composition harbored by bats in Guangxi-Vietnam border area, and inspected epidemiological situation and evolutionary characteristics of some viruses. Those findings provide fundamental data to cross-border transmission of bat viruses and predict bat virus-related zoonotic potentials.

Guangxi-Vietnam border region, bat, viral metagenomics, genetic diversity

doi: $10.1360 / \mathrm{N} 052018-00191$ 